\title{
Technostress Among Hotel Employees - a Longitudinal Study of Social Media as Digital Service Encounters
}

\author{
Karin Högberg ${ }^{(凶)}$ (1) \\ University West, 46131 Trollhättan, Sweden \\ karin.hogberg@hv.se
}

\begin{abstract}
The increasing implementation of digital technologies in organizations such as social media platforms is fundamentally transforming the nature of services encounters $[1,2]$, not least in the hospitality industry. This causes new ways of working for hotel employees, causing disruption in service routines and work tasks. There are few qualitative studies that are focusing on the hospitality industry and technostress. The present study focus on technostress among employees in an international hotel chain. Data have been collected in eight European countries over a period of seven years. The Person-Technology fit model is used in order to identify and analyze stressors and strains deriving from social media use. The results indicate that techno stressors such as work overload, work-life conflict, and changing algorithms creates negative stressors. The study makes a theoretical contribution to technostress research in the Information Systems research as well as the hospitality research field by uncovering negative stressors and strains created over time.
\end{abstract}

Keywords: Technostress $\cdot$ Social media $\cdot$ Digital service encounters $\cdot$ Hotel organizations

\section{Introduction}

The increasing implementation of digital technologies in organizations such as social media platforms is fundamentally transforming the nature of service encounters $[1,2]$, not least in the hospitality industry. By using social media platforms as communication tools, they have also become important digital service encounters [3]. A digital service encounter happens whenever a customer interacts with an employee through technology, e.g. social media platforms or e-mail. The use of social media in hospitality has brought many new work practices [4], for example, new, immediate ways of stakeholder interaction [5] that are often viewed as a positive development with many benefits, both for organizations and stakeholders [4]. However, there are also challenges with the new communication paradigm. Recent research emphasizes that employees are confronted with large amounts of information, which may generate information overload [6], as well as work overload [7, 8]. Earlier research also points out that the use of social media in a work context can cause blurred boundaries between employees' private and professional lives. Recently, research has called for more 
practical insights to extend the knowledge about social media-induced stress on employees in the context of work [9-13]. The phenomenon of stress caused by the use of Information Technologies is discussed in research under the term technostress [6, 8]. Technostress is related to several negative outcomes, such as physical, psychological, or behavioral strain. Stress represents the condition of discrepancy experienced by an individual between the demands of a given situation and the individual's capacity to meet them [14]. This can have consequences for employees, e.g. physical strains, but also for the organization as such, through lower employee job satisfaction and motivation $[6,16]$.

Recently, research has started to study technostress in the context of social media and the workplace $[5,17]$. This is due to the fact that social media increasingly pervade professional and personal life and are becoming more and more ubiquitous in work settings [6-8]. Such research has empirically validated that social media-induced technostress does exist, that the presence of social media-induced technostress is critical in the context of work [5], and that the increasing use of digital technologies in service encounters is closely related to employee technostress [18]. A large stream of research on social media-induced technostress has focused on private social media use in the workplace [19]. Research on technostress relies mostly on two methods, questionnaire and/or experimental investigations stimulated by hypotheses to assess perceived stress and what causes it $[16,18,20,21]$. Both techniques have limitations in the degree to which they capture the contextual contingencies of a stressful situation: the first because it relies on participant recall, while the simulated environment of the second may not reflect real life. That is, both techniques are appropriate for testing whether a particular phenomenon causes stress, but neither technique is appropriate for finding what stimulates stress in the workplace [22]. Additionally, little focus has been given to the context of the hospitality industry and employees concerning their experience of technostress and digital service encounters [23].

Considering the research gap and the importance of the topic, the aim of the present paper is to expose and explain stressors experienced by hotel employees at work when using digital service encounters, in this case social media platforms, over time. Hence, the present study extends the existing literature of social media-induced technostress. The following research question is asked: How do hotel employees experience technostress related to digital service encounters in social media platforms? A study of hotel employees in an international hotel chain is the context of the study. The theory of Person Technology fit [6] has been used as an interpretive lens for analyzing social media-induced stress in the context of the hotels. The theory of Person Technology fit was chosen due to its explanatory power, which can enable a richer interpretation of social media-induced technostress. As a theoretical contribution, stressors and strains deriving from digital service encounters and social media use over time are exposed and analyzed, which contributes to the Information Systems research field as well as hospitality and service research. 


\section{Related Research}

\subsection{Technostress}

Organizational stress typically includes individuals' perceptions of the demands placed on them by challenging stimuli, known as "stressors," and their psychological responses to such demands, known as "strains" [6]. Stressors represent "demands, stimuli, or conditions encountered by individuals in the work/organizational environment as factors that create stress," and strain refers to "the behavioral, psychological, and physiological outcomes of stress that are observed in individuals" [16, p. 419]. Examples of stressors in the workplace may include role ambiguity, conflict, and work overload, while examples of strain may include job satisfaction, organizational commitment, and turnover intention [16]. The information systems (IS) research field has long emphasized the stressor-strain relationship [1, 5, 7], which highlights the stress induced by rapid technological changes, time pressure and work overload, to mention a few [7], which is an approach that has been termed technostress. The term technostress was coined by Brod who described it as a "modern disease of adaptation caused by an inability to cope with the new computer technologies in a healthy manner" [24, p. 16]. Weil and Rosen [25, p. 5] developed Brod's definition by viewing technostress as "any negative impact on attitudes, thoughts, behaviors, or body physiology that is caused either directly or indirectly by technology." Research on technostress emphasizes that technostress can be attributed to continuous multitasking, re-learning and insecurity related to one's work tasks, as a consequence of frequent IT paradigm changes [18]. To understand IT-induced stress, researchers emphasize it is important to identify manifestations of the technologies themselves and for example focus on the question of what it is about technologies that eventually leads to stress. Theoretically, the outcomes of stress depend on how a person experiences the technology and stress. When stress is appraised positively, the outcomes are desirable. However, when stress is experienced negatively, it gives undesirable outcomes [26].

\subsection{Social Media in Organizations}

Social media platforms refer to technology artefacts that enable various actors to produce user-generated content, develop and maintain connections and social relationships, or enable other computer-mediated interactions and collaborations [27]. In the context of social media in the workplace, there are several research streams such as public social media, [2], enterprise social media, enterprise social software, and corporate social software [12]. Public social media such as Facebook and Twitter are often used by organizations for marketing and sales purposes and to create relationships with customers [2]. This can be compared to enterprise social media that are used for internal communications or internal knowledge exchange within organizations [12]. In 
the present paper, the definition stated by Van Osch and Coursaris [27, p. 54] of social media used by organizations is used:

technology artefacts, both material and virtual, that support various intra- and extraorganizational actors - including management, employees and external stakeholders - in a multiplicity of organizational communication activities for producing user-generated content, developing and maintaining social relationships, or enabling other computer-mediated interactions and collaborations in the context of a specific organization and its environment.

In contrast to other definitions, it includes both internal and public social media use and hence involves a wider range of social media use by organizations. Hence, Van Osch and Coursaris's definition was chosen since it is common that organizations use a range of social media platforms for various purposes [2, 39]. Based on previous research [cf. 2, 6], social media-induced technostress is defined in the present study as any negative impact on attitudes, feelings and behaviors that is stimulated by using social media in a work-related context. Recently, social media-induced technostress has been studied, focusing on different aspects. For example, one stream of research focuses on the private use of social media during work hours [5, 28] while another stream of research shows the implications of constant connectivity [2]. Van Zoonen et al. [29] claimed that work-related social media created boundary conflicts for employees [30]. Maier et al. [17] investigated conflicts related to work-home conflict and the technostress related to this. Kahn and Mahapatra [28] investigated social media as an inhibitor for technostress compared to other information systems and its impact on employee productivity.

\section{Theoretical Framework: Person Technology Fit Model}

In order to understand the advent of technostress related to social media the present study follows Ayyagari [6] and uses the Person Technology fit model, which has the purpose of identifying what causes stress related to IT in the workplace. Pervasive access to social media can induce people to engage in excessive use at work, which can promote technostress. This study thereby uses the P-T fit model of stress to examine the social media-induced technostress phenomenon. The model proposes usability features that are related to the adoption and use of technologies. Usefulness refers to the individual's perceived ability to do more, and complexity to increased work demanded by IT. The authors argue that these characteristics have been the basis of voluntary adoption of ICT, in order to predict adoption and use. However, they also point out that in the present technological context at the workplace, there is usually not a choice for adoption and use of ICTs due to the requirements of the job, which also suggests that individuals might have low perceptions of usability features. Furthermore, the authors point out the pace of change which relates to the dynamic nature of ITs. Finally, the category of intrusive features refers to the invasiveness of ITs, i.e., presenteeism, the degree to which the technology enables users to be reachable and anonymous (see Fig. 1). The P-T model also identifies stressors, under the categorization of work overload, i.e., the perception that assigned work exceeds an individual's capability and relates to role ambiguity, invasion of privacy and work-home conflict. The category of 
role ambiguity is the unpredictability of the consequences of the users' performance. This is also related to role overload, which "has considerable overlap with work overload" [6, p. 835]. Role overload arises when employees face too many work requests in relation to the time they have available. Arguably, digital technology forces employees to work more and adapt their work routines to fit into digital service encounters as well as physical ones [31]. Furthermore, they are forced to invest more work time in learning and adapting to how to control digital technologies and integrate them into their daily routines, which often results in work overload [32]. This requirement often results in an excess of tasks [32] and creates or intensifies role overload. Such an excess of tasks may also occur if unreliable technology forces employees to repeat digital inputs or to restart a system. Work-home conflict is the perceived conflict between the demands of work and family and invasion of privacy involves the perception that an individual's privacy has been compromised (see Fig. 1). The stressors can in turn bring about strains, such as reduced productivity, lack of innovation, burnout and less organizational loyalty and commitment [15].

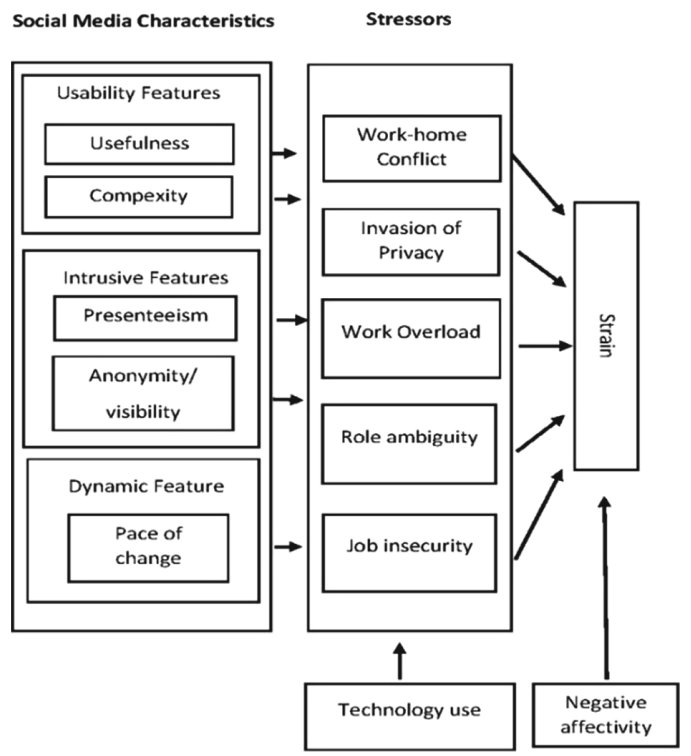

Fig. 1. Technostress framework, adapted from Ayyagari et al. [6]

\section{Research Setting and Methodology}

The empirical data presented in this paper is part of a larger research project [40] of organizational social media use in an international hotel chain. The case study focuses on the implementation and early use as well as continuous use of social media in 14 hotels in eight European countries within the hotel chain. For this study an interpretative approach had been adopted, building on case study design [33]. This is because 
the aim is to understand the phenomenon, social media-induced stress, through the meanings that individuals ascribe them [33]. Hence an interpretative methodology is appropriate since the aim is to gain insight into the hotel employees' experiences of stress and strains induced by social media use over time in a work context. Due to the longitudinal design of the study, the hotel employees' early interpretations of the introduction and use as well as use over time have been studied. Collecting data over a period of seven years gave the possibility of exposing social media use over time with its stressors and strains, not just the implementation phase or a snapshot in time.

\subsection{Data Collection}

A number of different data collecting methods have been used, including interviews, workplace observations, online observations, and written materials such as social media policies and strategies. Interviews were the main source of empirical data. The interviews were conducted in a narrative form [34] to gain understanding into the employees' concrete experiences of technostress induced by social media. Narratives can be useful for revealing detailed explanations of individual IT use and behavior [35]. The primary data collection technique was based on 58 semi-structured interviews conducted with 32 hotel employees. Of these, 22 were follow-up interviews. Hence, empirical data was collected both in the immediate implementation phase of social media in the 14 hotels and later. Thereby, employees early interpretations of social media use at work and their experiences and adoption to daily work practices could be uncovered. By doing regular follow-up interviews and observations, data concerning the changes of use, interpretations and experiences over time could be collected. Also, studying the social media use over time gave insights into where and how digital service encounters took place and evolved.

The interviews were conducted in eight European countries between 2013 and 2020 and lasted between 60 and 90 min. Half of the employees were women, and half were men. Their age ranged from 23 to 43 . The employees' private use of social media varied from using with low interest to being very active users. Altogether, the interviewed employees had varying professional statuses including marketing manager, sales manager, front office manager and CRM manager. However, all of them had social media use included in their work practices, hence social media use was mandatory for these employees. By studying the employees in their natural settings insights into the employees' daily social media work practices could be uncovered. Furthermore, the understanding of how the employees interacted with customers in digital service encounters in social media platforms increased by doing online observations. Furthermore, written materials and documentation, such as social media strategies and policies, functioned as contextual information. Hence, gathering narratives from the hotel employees gave insights into stressors and strains related to the use of social media. Hence the users were asked to thoroughly describe service encounters taking place in social media platforms, how they experience these encounters and situations and other stressors related to the social media introduction and ongoing use and how this had affected them in their work but also private life. More detailed followup questions were also asked in order to expose stressors and strains. To understand the work/life relationship to organizational social media, the employees were asked to 
describe their private use of social media. Essentially, this narrative approach allowed the employees to describe their experiences of social media in their own words without being restricted to or guided by the researchers' terminology. Hence, speculation and hypothetical scenarios could be avoided [36].

\subsection{Analysis}

In the present study, the unit of analysis was the individual hotel employee's perception of technostress, i.e., stressors and strains deriving from the use of multiple organizational social media for digital service encounters. The analysis process used was inductive, grounded in the empirical findings. The coding process started with open coding which resulted in identifying several themes in the data related to stress induced by social media. Thereafter categories from the P-T fit framework [6] were used, i.e., technology features, use, stressors and strains. Strauss and Corbin's [37] recommendations to do axial coding after open coding was used. However, this method was treated as a method through which to discern relationships in the data, not as an overly restrictive set of methodological rules [38]. Examples of these labels include "working after hours," "always being available" and "lack of understanding and knowledge." In the following step, the recurrent patterns of social media use and stressors were emphasized as well as the strains from these stressors. Furthermore, the strains were related to their causes and what technological features/characteristics had caused the stress (see Table 1). The data was triangulated by ensuring that main insights were repeated in multiple interviews [33].

Table 1. Axial coding schemes and examples from data

\begin{tabular}{|l|l|l|}
\hline Category & Description & Examples from data \\
\hline SM characteristics & \multicolumn{2}{|l|}{} \\
\hline Visibility & $\begin{array}{l}\text { Published content in SM is } \\
\text { visible to a big audience and } \\
\text { difficult to erase }\end{array}$ & $\begin{array}{l}\text { "I thing twice before I post because everyone can see if I } \\
\text { make a mistake" }\end{array}$ \\
\hline Push notifications & $\begin{array}{l}\text { Automatic notifications from } \\
\text { SM platforms when users } \\
\text { interact }\end{array}$ & "There is a constant flow of notifications" \\
\hline $\begin{array}{l}\text { Real-time } \\
\text { interactions }\end{array}$ & $\begin{array}{l}\text { Real-time encounters with } \\
\text { guests and colleagues }\end{array}$ & "Everything goes on in all these digital places at once" \\
\hline SM stressors & \multicolumn{2}{|l|}{} \\
\hline Work overload & SM causes more workload & $\begin{array}{l}\text { "It [SM] gives us so much more to do, so many more } \\
\text { things to keep up with, and it feels like you are never } \\
\text { done." }\end{array}$ \\
\hline Reachability & $\begin{array}{l}\text { Smartphones and SM make it } \\
\text { possible to always be reached }\end{array}$ & "I am constantly connected, always online." \\
\hline Work-home conflict & $\begin{array}{l}\text { The use of SM at work blurs } \\
\text { boundaries between work } \\
\text { and private life }\end{array}$ & $\begin{array}{l}\text { "I feel very loyal to both my colleagues and to our guests } \\
\text { so I never turn my phone off." }\end{array}$ \\
\hline Digital encounters & $\begin{array}{l}\text { SM are new encounters for } \\
\text { service }\end{array}$ & "We are really encouraged to answer all questions fast" \\
\hline $\begin{array}{l}\text { Changing } \\
\text { algorithms }\end{array}$ & $\begin{array}{l}\text { SM are constantly changing } \\
\text { features }\end{array}$ & $\begin{array}{l}\text { "I try to keep up with all the new stuff but it's really hard } \\
\text { because it keeps changing." }\end{array}$ \\
\hline Strains & $\begin{array}{l}\text { Does not prioritize social } \\
\text { media }\end{array}$ & $\begin{array}{l}\text { "I give service to the guests at the hotels, then I take on } \\
\text { social media" }\end{array}$ \\
\hline
\end{tabular}




\section{Findings}

\subsection{Multiple Organizational Social Media}

Many of the employees express that they use many different types of social media platforms in their daily work practices. For example, Facebook and Instagram are used by all employees and many of them also use LinkedIn and Twitter. Furthermore, thirdparty platforms such as TripAdvisor are important platforms for the hotels, because many guests use them to review the hotel. This created a numerous amount of digital service encounters to manage and keep up with. The employees emphasize that it is "an impossible task" to keep up with the development and changes in current social media platforms as well as the encounters with hotel guests. The employees experience that their current knowledge of workplace technologies and social media soon loses its relevance as they are quickly replaced or changed. The constant change of trying to keep up with these developments is stressful and the employees do not always consider it worth the effort. Many employees says that social media platforms are not technologically difficult to grasp per se, that is, there is not high complexity related to social media, but it takes time and frequent use to figure them out. The employees report that push notifications and alerts from the platforms make them stressed and that it is very hard "not to give them any notice," and that they disrupt their other work tasks. One of the employee says:

Whenever I see a red mark or hear the signal [push-notification], I just leave everything I do and look. It is annoying but I just can't seem to help it.

The employees also express that the push notifications reveal how fast they respond to customers and that it is a way for managers and other employees to keep track of how quickly the employees answer and interact with customers. Interestingly, most employees emphasize that they wish to prioritize the guests and the physical hotel, but experience that "most guests want us to be present all the time in social media and give them quick answers." Another important stressor underlined by the employees is the visibility that social media platforms provide. That is, what is written and published in social media is visible to others and very hard to delete. Bad behavior and conflicts can easily be shared and stored digitally. This makes the employees express that they think twice before they post answers to guests.

\subsection{Parallel Worlds}

The employees describe that social media has become a "parallel world" and that there is little integration between the social media platforms and e.g. their other IT systems. This causes a need to constantly shift between different technological devices such as smartphones and laptops. This is expressed as a source of stress for employees who point out that they feel "out of control and need to check everything all the time."

The characteristics of social media also had a stressful impact on the employees' work routines. The employees say that because hotel management encourages them to use social media platforms as service encounters and that the guests also view them as a good platform for encounters, they experience increased stress in relation to their work. 
They describe rearranged work routines and procedures and "parallel worlds." One of the employees says:

It is as if we live in two different worlds. The physical one at the hotel and then the digital. And everything goes so fast in the digital world. An hour is an eternity and if you don't answer fast enough you're out!

According to the employees' statements, the use of social media in a workplace setting does not make their work tasks more time effective, quite the opposite. Using social media takes a lot of time according to the employees and is often put "on top of everything else." The employees underline that in order to cope with the stress, they "ignore" and do not "prioritize" using social media, despite the demand from the hotel management.

\subsection{Private Life vs. Professional Life}

The empirical data suggest that the use of social media especially creates stress for employees because of increased availability. Due to ubiquitous internet access and use of smartphones, they experience that they need to always be available even when they are not working. Hence, the boundaries between their professional life and private life have been blurred and the employees find it difficult to find a balance. The importance of loyalty, both to colleagues and to guests are pointed out as a stressor. That is, the employees express that they choose to be available at all times in order to do a good job and provide good service, instead of prioritizing their private life. Most employees say that they do not turn off their work phone when they are not at work. One employee says:

I believe that our kind of people [hoteliers] want to give good service and it is very hard for us to turn off that side of us, even when we are off duty. I want to be there for my colleagues as well, and I want them to be there for me as well.

The example above illustrates an issue that is commonly regarded as problematic among the employees. However, they all express an "unspoken agreement" that one should be available, so that good service can be provided.

\section{Discussion}

The present longitudinal qualitative study contributes to the existing literature on social media-induced technostress within the hospitality industry with respect to social media as digital service encounters. In contrast to earlier research (cf. [11]), which focused on stressors that occur during the implementation phase, the present study investigated long-term social media-induced stressors perceived by employees over a seven-year period. A first reading of the findings confirms many of the established insights from both information system research (cf. [16]) and organizational research (cf. [17]). For example, the case confirms earlier research discussion about workload, work/life balance and availability. Based on the data, the characteristics of social media cause stressors. The visibility $[6,39]$ made possible by social media characteristics stands out 
as one stressor for the employees. Many of them argue that they are more insecure about how to answer a guest in social media channels than in a "face-to-face" situation. This also illustrates that the guests can be more anonymous in social media, as the faceto-face interaction is missing. Furthermore, it illustrates the new routines and work practice related to "service encounters 2.0," that is, service encounters taking place using digital technologies [3]. The visibility gives other members of the organizations such as managers and colleagues as well as stakeholders such as guests, the possibility to see how individual employees communicate and behave in social media including what they post [39]. Features like real-time interactions and reachability were emphasized as stressors, which also blurred boundaries between the employees' private and professional lives [16]. Obviously, being available is a part of the hotels organizations culture but also an important part of the employee's professional identity Furthermore, the study reveals a high degree of presence connected to stressors. The features of social media contain constant push notifications [6, 39]. The constant alerts from social media at all hours of the day called for employees that were eager to provide good service, but also to be present and alert on enterprise social media platforms, to the detriment of their private lives. In the present paper, third-party platforms such as TripAdvisor and Booking.com have been included, in order to identify stressors deriving from these platforms and the service encounters that take place there. The data reveals that social media redundancy, i.e., the use of a range of social media platforms for a variety of purposes, created a lack of synchronization, both between the social media platforms and with other IT used in the organizations. As stated by the employees, the use of multiple social media created a flexible way of working, but also blurred the boundaries concerning life and work, and hence can be linked to a high degree of privacy intrusion [6]. The pace of change [6], i.e., the changing algorithms in social media platforms, was described as a stressor. Many employees expressed the feeling of lagging behind the constant change of social media algorithms and features.

\section{Conclusions, Limitations and Future Research}

The increasing use of many different social media platforms in organizations has been associated with negative side effects such as technostress [16-18]. While prior studies concerning social media-induced stress have provided valuable knowledge regarding social media stressors, they have not examined the associated stressors related to using social media as service encounters over time. Therefore, the present study aimed to explore this area of research and hence contribute to both information systems research as well as hospitality research. The present study revealed that social media use could contribute to lack of synchronization between social media and other IT as well as intrusion in private life and work overload.

The study has several limitations. Although the case study design allows deep insights into the stressors and strains linked to social media, only one company was studied, and thus the generalizability of the findings is limited. Future research could complement the findings by, for example, analyzing other hotel organizations and 
combining the qualitative method with quantitative methods in order to create a greater understanding of stressors.

The study also has practical implications. By identifying and linking stressors induced by social media, organizations and managers can recognize strains and create an understanding of why they emerge and avoid creating them. Also, the notion that hotel employees take pride in being accessible around the clock, since they associate this with providing good service, is relevant to acknowledge in service organizations such as hotel organizations.

\section{References}

1. Huang MH, Rust RT (2013) IT-related service: a multidisciplinary perspective. J Serv Res 16(3):251-258

2. Van Doorn N (2017) Platform labor: on the gendered and racialized exploitation of lowincome service work in the 'on-demand' economy. Inf Commun Soc 20(6):898-914

3. Larivière B, Bowen DE, Andreassen TW, Kunz W, Sirianni NJ, Voss CA (2017) "Service encounter 2.0": an investigation into the roles of technology, employees and customers. J Bus Res 79:238-246

4. Aral S, Dellarocas C, Godes D (2013) Introduction to the special issue - social media and business transformation: a framework for research. Inf Syst Res 24(1):3-13

5. Bucher E, Fieseler C, Suphan A (2013) The stress potential of social media in the workplace. Inf Commun Soc 16(10):1639-1667

6. Ayyagari R, Grover V, Purvis R (2011) Technostress: technological antecedents and implications. MIS Q 35:831-858

7. Stephens K, Cho J, Ballard D (2012) Simultaneity, sequentiality, and speed: organizational messages about multiple-task completion. Human Commun Res 38(1):23-47

8. Tarafdar M, Cooper JF, Stich CL (2019) The technostress trifecta-techno eustress, techno distress and design: theoretical directions and an agenda for research. Inf Syst J 29(1):6-42

9. Chen L, Muthitacharoen A (2016) An empirical investigation of the consequences of technostress: evidence from China. Inf Resour Manag J (IRMJ) 29(2):14-36

10. Dittes S, Smolnik S (2017) Why are we doing this again? Towards uncovering the outcome perspective of enterprise social software use. In: Proceedings of the ECIS 2017

11. Forstner A, Nedbal D (2017) A problem-centered analysis of enterprise social software projects. Procedia Comput Sci 121:389-397

12. Leonardi PM, Huysman M, Steinfield C (2013) Enterprise social media: definition, history, and prospects for the study of social technologies in organizations. J Comput-Mediat Commun 19(1):1-19

13. Moqbel M, Kock N (2018) Unveiling the dark side of social networking sites: personal and work-related consequences of social networking site addiction. Inf Manage 55(1):109-119

14. Cooper CL, Dewe PJ, O'Driscoll MP (2001) Organizational stress: a review and critique of theory, research, and applications. SAGE, New York

15. Ragu-Nathan TS, Tarafdar M, Ragu-Nathan BS, Tu Q (2008) The consequences of technostress for end users in organizations: conceptual development and empirical validation. Inf Syst Res 19(4):417-433

16. Tarafdar M, Tu Q, Ragu-Nathan BS, Ragu-Nathan TS (2007) The impact of technostress on role stress and productivity. J Manage Inf Syst 24(1):301-328 
17. Maier C, Laumer S, Eckhardt A, Weitzel T (2014) Explaining technical and social stressors in techno-social systems: theoretical foundation and empirical evidence. In: Maier $\mathrm{C}$ (ed) Technostress: theoretical foundation and empirical evidence, Munich

18. Christ-Brendemühl S, Schaarschmidt M (2020) The impact of service employees' technostress on customer satisfaction and delight: a dyadic analysis. J Bus Res 117:378-388

19. Brooks S, Califf C (2017) Social media-induced technostress: its impact on the job performance of it professionals and the moderating role of job characteristics. Comput Netw 114:143-153

20. Wang K, Shu Q, Tu Q (2008) Technostress under different organizational environments: an empirical investigation. Comput Hum Behav 24(6):3002-3013

21. Tu Q, Tarafdar M, Ragu-Nathan TW, Ragu-Nathan BS (2008). Improving end-user satisfaction through techno-stress prevention: some empirical evidences. In: Proceedings of the AMCIS 2008, p. 236

22. Schellhammer S, Haines R, Klein S (2013). Investigating technostress in situ: understanding the day and the life of a knowledge worker using heart rate variability. In: 2013 46th Hawaii International Conference on System Sciences, January. IEEE, pp 430-439

23. Farrish J, Edwards C (2019) Technostress in the hospitality workplace: is it an illness requiring accommodation? J Hospital Tour Technol 11:83-92

24. Brod C (1982) Managing technostress: optimizing the use of computer technology. Pers $\mathbf{J}$ 61:753-757

25. Weil MM, Rosen LD (1997) Technostress: coping with technology@ work@ home@ play. Wiley, New York, pp 29-32

26. LePine JA, Podsakoff NP, LePine MA (2005) A meta-analytic test of the challenge stressorhindrance stressor framework: an explanation for inconsistent relationships among stressors and performance. Acad Manage J 48(5):764-775

27. Van Osch, W, Coursaris CK (2013) Organizational social media: a comprehensive framework and research agenda. In: 2013 46th Hawaii international conference on system sciences, January. IEEE, pp 700-707

28. Khan A, Mahapatra M (2017) The impact of social media as technostress inhibitor on employee productivity. In: Proceedings of the 2017 ACM SIGMIS conference on computers and people research, June, pp 113-116

29. van Zoonen W, Treem JW (2019) The role of organizational identification and the desire to succeed in employees' use of personal Twitter accounts for work. Comput Hum Behav 100:26-34

30. Ali-Hassan H, Nevo D, Wade M (2015) Linking dimensions of social media use to job performance: The role of social capital. J Strat Inf Syst 24(2):65-89

31. Thatcher JB, Stepina LP, Boyle RJ (2002) Turnover of information technology workers: Examining empirically the influence of attitudes, job characteristics, and external markets. J Manage Inf Syst 19:231-261

32. Krol G (2017) Individual differences in dealing with overflow. Eur Manage J 35(6):794-802

33. Myers MD, Avison D (eds) (2002) Qualitative research in information systems: a reader. Sage, New York

34. Myers MD (2019) Qualitative research in business and management. Sage, New York

35. Pentland BT (1999) Narrative methods in collaborative systems research. In: Proceedings of the 32nd annual Hawaii international conference on systems sciences 1999, HICSS-32. Abstracts and CD-ROM of full papers, January. IEEE. https://doi.org/10.1109/hicss.1999. 772719

36. Gruen DM, Sheldon MA, Vaithaynathan S (2002) U.S. Patent No. 6,393,460. U.S. Patent and Trademark Office, Washington, DC 
37. Strauss AL, Corbin JM, Niewiarra S, Legewie H (1996) Grounded theory: grundlagen qualitativer sozialforschung. Beltz, Psychologie-Verlag-Union, Weinheim

38. Urquhart C (2007) The evolving nature of grounded theory method: the case of the information systems discipline. The sage handbook of grounded theory. Sage, New York, pp 339-359

39. Treem JW, Leonardi PM (2012) Social media use in organizations exploring the affordances of visibility. Edit Pers Assoc Commun Yearbook 36:143-189

40. Högberg K (2018) Persistent digital service encounters: challenges of organizational use of social media in a hotel chain (Doctoral dissertation, University West)

Open Access This chapter is licensed under the terms of the Creative Commons Attribution 4.0 International License (http://creativecommons.org/licenses/by/4.0/), which permits use, sharing, adaptation, distribution and reproduction in any medium or format, as long as you give appropriate credit to the original author(s) and the source, provide a link to the Creative Commons license and indicate if changes were made.

The images or other third party material in this chapter are included in the chapter's Creative Commons license, unless indicated otherwise in a credit line to the material. If material is not included in the chapter's Creative Commons license and your intended use is not permitted by statutory regulation or exceeds the permitted use, you will need to obtain permission directly from the copyright holder.

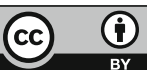

